[Peters, M., \& Roberts, P. (1998). Agendas for Change: Universities in the 21st Century. New Zealand Annual Review of Education, 7, 5-28]

\section{Agendas for Change: Universities in the 21st Century}

\section{MichaEl PETERS AND PETER ROBERTS}

\section{Abstract:}

This article provides a critical discussion of two recent policy documents on tertiary education: the Tertiary Review Green Paper in New Zealand and the Dearing Report in the United Kingdom. Brief reference is also made to the interim report of the West Committee in Australia. Pivotal differences between the Green Paper and the Dearing Report are identified under four headings: the concept of education, resourcing, globalisation, and the role of the humanities. The authors argue that the Green Paper represents a further step toward a fully consumer-driven system of tertiary education in New Zealand. The Dearing Report provides a more expansive educational ideal in the notion of "The Learning Society". While not devoid of potential problems, the Dearing Committee's ideal recognises both the need for change in a globalised world and the importance of preserving intellectual and cultural traditions through the arts and humanities.

t is not coincidental that several OECD countries - the United Kingdom, Australia and New Zealand among them - are currently engaged in the process of reviewing their tertiary education systems. It is now widely believed that higher education contributes to economic development in a variety of ways, not only in terms of direct improvements in productivity but also through research and development and, in particular, innovation and so-called "technology transfer". Recent work in growth theory has concentrated on the importance of "human capital" and externalities accruing to higher education. ${ }^{1}$ Higher education systems provide scientists, engineers and other skilled professionals, who, in turn, help to determine productivity growth. This renewed emphasis on the relationship between higher education and economic growth follows in the wake of nearly fifty years of theorising concerning advanced western economies. In the late sixties both Daniel

\section{Michael Peters and Peter Roberts}

Bell (1974) and Alain Touraine (1974) (though from different perspectives) began to talk of "post-industrial societies" where the axial institutions were deemed to be those responsible for the production of knowledge. These ideas were developed further by Fritz Machlup (1962) and Marc Porat (1977) who attempted to measure the growth and contribution of service industries, and particularly information industries, to the American economy. In the late 1970s and early 1980s, other thinkers, such as the Japanese sociologist and futurist, Yoneji Masuda (1981), construed the post-industrial society as "the information society", emphasising the magnitude of the changes by pointing to a shift in the nature of production. Knowledge and information, he argued, should be seen as the raw materials for the tertiary, quaternary, and quintennial industries of the future in the same way that coal and iron ore were raw materials for secondary industries during the industrial revolution and thereafter.

Theoretical developments based upon notions of the "post-industrial society", "information society", and more recently, the "information economy" (and "information superhighway") have also become part of the neo-liberal policy agenda. Beginning in the 1980s, the world policy institutions - the World Bank, the International Monetary Fund, and the Organisation for Economic Cooperation and Development - encouraged their member countries to adopt a range of structural adjustment policies. These included: the abolition of tariffs and subsidies, a floating exchange system, a commitment to "free" trade, privatisation of key state assets, restructuring and commercialisation of the remaining public sector, and the adoption of a fiscal austerity programme. The effect of this set of neo-liberal monetarist policies has been to reinforce existing trends toward globalisation and internationalisation, dismantling trade barriers and eroding national sovereignty. These policies have also created the ideal conditions in which new mega information, communications and media transnational corporations have grown and flourished. They have contributed to the development of a global finance capitalism. These trends have encouraged national governments to focus attention upon trade and competition as the full realities of what it means to participate successfully in the global economy begin to be realised.

In these changed conditions, higher education systems become one of the key touchstones for future development and competition: a crucial arena in which these trends, forces and policies meet and criss-cross one another. This chapter compares two visions of tertiary 
education: the view broadly embraced by the present Coalition government in New Zealand (National/New Zealand First) and the alternative furnished by the Dearing Committee in the United Kingdom. The first can be described as a pure neo-liberal market model of tertiary education; that is, a fully consumer-driven system. The second is neatly encapsulated in the Dearing Committee's notion of "The Learning Society". The former, driven by the ideology of the New Right, is narrow in its vision and complacent in its expectation that the market will provide all the answers to educational questions. It seeks to obliterate distinctions between education and training, vocational and academic learning, and universities and other tertiary institutions. There is little recognition of the public service functions of universities (their larger cultural and social functions), and the statutory role of the university as critic and conscience of society is undermined. By contrast, the latter is broad in its vision and is strongly committed to the traditional roles and functions played by universities. At the same time, the more expansive vision of "The Learning Society" recognises the distinctive features of the current historical moment (including the importance of "information" as a commodity in contemporary economies) and confronts, in a rigorous and investigative manner, the new expectations and challenges facing tertiary educators in the 21st century.

The paper falls into four parts. The first two sections sketch some of the key elements in the Tertiary Education Review Green Paper (Ministry of Education, 1997a) and the Dearing Report (Dearing, 1997) respectively, while the third addresses some of the pivotal differences between the two documents. Given space constraints, we confine the discussion to four important issues: the concepts of education, resourcing, globalisation, and the role of the humanities. Other themes - the role of the new information technologies in tertiary education, for example - have been investigated at length elsewhere (Peters and Roberts, 1998). The fourth section provides a snapshot of one scenario for the future of higher education in this country.

Acknowledgement should also be made of evaluative work on the Green Paper already undertaken by others. Boston (1997a), for example, offers a detailed overview and critique of the document, drawing attention to its lack of in-depth analysis, incomplete treatment of funding issues, and neglect of the principles on which higher education institutions have been founded, among other areas of weakness. Against the radical transformation implied by the Green Paper, Boston argues a case for maintaining a modified version of the present bulk-funding regime for tertiary education. Changes might include "a reduction in the number of funding categories, the introduction of multi-year funding arrangements, ... opportunities for private providers to have greater access to public funds", and the abandonment of "study right/non-study right funding distinctions" (p. 23). On the question of research funding, Boston favours a mix of student-driven funding and competitive bidding (with a stronger emphasis on the latter). He supports the introduction of a more robust system of ownership monitoring while also calling for improvements in the system of ministerial appointments to tertiary governing bodies. (See also Boston, 1997b.)

We believe that should New Zealand follow the path set out in the leaked Ministry of Education document, the result will closely resemble the vision conveyed in an appendix to a third major report on tertiary education: the West Committee's policy discussion paper, Review of Higher Education Financing and Policy (West, 1997). The appendix was produced by Global Alliance Limited (1997) for a review of higher education in Australia, but it could just as easily have served as a blueprint for the fully consumer-driven system envisaged, albeit in only superficial detail, by the authors of the leaked Ministry of Education document (Ministry of Education, 1997b), released prior to the publication of the official Tertiary Education Review Green Paper. We conclude that both statements should be regarded as serious proposals, heralding a radically different, highly marketised and customised educational future.

\section{New Zealand's Tertiary Education Review}

The Tertiary Education Review Green Paper (Ministry of Education, 1997a), one part of a wider review process foreshadowed in the National/New Zealand First coalition agreement, was made available for public viewing on 11 September 1997. This followed the release, some weeks earlier, of a leaked Ministry of Education document (Ministry of Education, 1997b). The leaked document quickly found its way into the hands of various educational and media groups, and prompted a wave of protests from students and tertiary staff across the country. While the proposed move toward greater privatisation in the educational sector was not unexpected, and indeed had been under way for some years, the scale of the changes signalled in the leaked document surprised many people. Here, it seemed, was the neo-liberal model of tertiary 
education in its purest form to date. Vouchers, long lobbied for by powerful business organisations such as the New Zealand Business Roundtable and many politicians in the National governments of 1990-1993 and 1993-1996 (former Minister of Education, Lockwood Smith, was in favour of them, as was Simon Upton, 1987), would be put in place. Traditional governance arrangements would be greatly altered: under a Crown company-type structure the Government would appoint all members of the Council and the Council would be reduced in size. In effect a "board of directors" business model would be substituted for the present "democratic" model of governance. Both faculty and students would lose representation on Councils and the Vice-Chancellor would no longer be a member. Teaching would be separated from research, and competitive bidding for research funds would be encouraged. Government subsidisation of tertiary fees would diminish, with students paying an increasing proportion of the costs associated with their studies.

The Green Paper (entitled A Future Tertiary Education Policy for New Zealand) echoes the focus on fiscal constraint so dominant in the leaked document, but exhibits a different style in discussing significant areas of tertiary policy. Under the guise of an apparent openness, the Government - through the Ministry of Education - sets out policy possibilities (on questions of tuition, research, governance, etc.) in the form of options. While there are variations in the number and range of options in different sections, the general format in each case is the same: one option typically shows a close correspondence with the policy direction signalled in the leaked document while the alternatives are more closely aligned with current policies or practices. With only a few exceptions, then, the changes set out in the leaked document remain possibilities in the official version of the Green Paper .

Many of the key features of the Green Paper are summarised in the Overview accompanying the document. The tertiary review, it is noted, is "being undertaken on the assumption that the limited resourcing currently available to the tertiary sector can be used better" (p. 1). The Government's expressed aim is to evaluate "the ways in which existing spending can be made more effective - in both achieving higher participation rates and supporting a high-quality, dynamic, and innovative tertiary sector" (p. 1). It is stressed that the proposals advanced in the Green Paper do not represent a "final Government position"; the intention is to inform readers of the Government's thinking to date and to foster discussion and debate (pp. 1, 8). Following the consideration of submissions from interested groups, the Government intends to publish a White Paper in 1998, informed by work in other policy areas, including: the Employment Strategy, the National Qualifications Framework (Ministry of Education, 1997c), the Review of Student Support, the Maori Education Strategy and the Teacher Education Review (Ministry of Education, 1997d). ${ }^{2}$

Beginning from the proposition that New Zealand's "greatest asset is its people", the Government summarises the purposes of tertiary education thus:

Tertiary education is central to New Zealand and New Zealanders successfully meeting the challenges of the future. Tertiary education enables personal and professional growth, and contributes significantly to the richness of our society and the lifestyles of New Zealanders. It is central to the future positioning of New Zealand in the global economy, where the competitive advantage of industry and business will depend more on the knowledge, skills, adaptability, and innovation of our workforce and its leaders. (p. 1)

The report identifies three major "forces" expected to shape demands on tertiary education over the next twenty years. First, there is the question of access and the range of people demanding a variety of courses and learning opportunities. Second, tertiary education will become internationalised, reflecting the need for global standards, encouraging relationships between New Zealand and overseas "providers", and creating a global market. Third, developments in information technology will break down national and international barriers to tertiary education and alter the way it is delivered (p. 2). In this context, the report delineates the following goals for the tertiary sector (p. 3):

- Improving opportunities for participation

- Improving the participation and achievement of currently under-represented groups

- Encouraging high quality qualifications, programmes, and providers

- Encouraging value for the students' and the Government's financial contribution.

While acknowledging that the tertiary sector has made "much progress" since the last major set of reforms in 1989, it is noted that "further improvements need to be made to ensure high quality, innovation, and responsiveness". The following current policy issues are identified (pp. 3-4): 
- Better ways of getting subsidies to students

- The need for incentives to keep costs low

- The need to encourage innovation and responsiveness

- The need for more consistent quality

- The need for better information

- The need for improved governance and accountability of tertiary education institutions.

In terms of indicating future directions for reforms, the Government focuses on a "coherent" approach to questions of resourcing, regulation, ownership and governance (p. 4). The Green Paper canvasses two major choices concerning the resourcing of tuition: "to share resources across all students irrespective of age or the amount of tertiary education they have already had"; or, "to allocate to all students a fixed amount of government subsidy for their tertiary education" (p. 5). The second option - a student entitlement or vouchers scheme - appears to be the preferred Government position (as revealed in the leaked document). In terms of the resourcing of research, the report identifies two key issues: first, the question of whether all degree providers, or only postgraduate degree providers, should carry out research activities; second, the question of how resources for research might be allocated (p. 6). The Government intends to establish a "minimum quality requirement" (threshold) for tertiary qualifications, programmes and providers through the National Qualifications Framework (NQF) (p. 7). On matters of governance and accountability, the Government aims to encourage an ownership monitoring regime with mandatory reporting on matters of strategic direction and suitable financial performance indicators. The report countenances smaller councils and the possibility of establishing Tertiary Education Institutions (TEIs) as "Public Tertiary Education Institutions", based on the Companies Act 1993 (p. 7). Private Training Establishments (PTEs) - of which there are some 780 - would receive government funding, thus spreading the tertiary tax dollar even more thinly across the sector.

In short, the key areas of tertiary policy covered by the Green Paper include tuition, research, resourcing, governance, quality and regulation. The general directions signalled in the document have been summarised in a submission by the Association of University Staff of New Zealand (1997):

- to endeavour to increase participation in tertiary education and ensure the quality of that education - without increasing public expenditure;
- to encourage the expansion of private provision largely by funding Private Training Establishments at the same rate as public institutions;

- to ensure that the system is more heavily driven by individual student choice;

- to extend competition in the tertiary education sector rather than developing coordination and planning;

- to decrease each individual student's government tuition subsidy, as student participation increases overall;

- to place an overly optimistic belief in the benefits of providing information to students - to improve quality, choice and efficiency;

- to move away from representative university councils toward business-focussed Ministerial a ppointees operating under legislation based on the Companies Act 1993;

- to treat public education institutions as businesses - their assets to be vested in them and valued, with the requirement that payment be made to Government by way of a capital charge.

\section{The Dearing Report: A Vision of the Learning Society}

Higher education is fundamental to the social, economic and cultural health of the nation. It will contribute not only through the intellectual development of students and by equipping them for work, but also by adding to the world's store of knowledge and understanding, fostering culture for its own sake, and promoting the values that characterise higher education: respect for evidence; respect for individuals and their views; and the search for truth. Equally, part of its task will be to accept a duty of care for the wellbeing of our democratic civilisation, based on respect for the individual and respect by the individual for the conventions and laws which provide the basis of a civilised society. (Dearing, 1997, pp. $1-2)$

Carrying the title Higher Education in the Learning Society, the Dearing Report (1997) sets out a detailed vision of education and training in the United Kingdom over the next two decades. ${ }^{3}$ The Report begins from the proposition that education is "life enriching and desirable in its own right... [and] fundamental to the achievement of an improved quality of life in the UK" (p. 1). The Report speaks of the need to promote "world class" learning and research, and advocates a compact between "institutions and their staff, students, government, employers and society in general" in working toward this goal. In summarising the 
future envisaged by the Committee, the Report notes (p. 1) that higher education in the UK will need to:

- encourage and enable all students - whether they demonstrate the highest intellectual potential or whether they have struggled to reach the threshold of higher education - to achieve beyond their expectations;

- safeguard the rigour of its awards, ensuring that UK qualifications meet the needs of UK students and have standing throughout the world;

- $\quad$ be at the leading edge of world practice in effective learning and teaching;

- undertake research that matches the best in the world, and make its benefits available to the nation;

- ensure that its support for regional and local communities is at least comparable to that provided by higher education in competitor nations;

- $\quad$ sustain a culture which demands disciplined thinking, encourages curiosity, challenges existing ideas and generates new ones;

- be part of the conscience of a democratic society, founded on respect for the rights of the individual and the responsibilities of the individual to society as a whole;

- be explicit and clear in how it goes about its business, be accountable to students and to society, and seek continuously to improve its own performance.

The Report documents trends in higher education in the United Kingdom over the last thirty years, observing that participation rates have increased substantially in that time. Institutions of higher education have maintained their international standing for research while at the same time becoming more efficient and adapting to the changing "needs" of students. The Report notes that the recent funding cap on growth in undergraduate student numbers has had a deleterious impact on many staff in higher education and acknowledges concerns that "short term pressures to reduce costs, in conditions of no growth, may damage the intrinsic quality of the learning experience which underpins the standing of UK awards" (p. 2). Several areas for potential improvement in the higher education sector are signalled. These include: ensuring comparability in quality standards; improving collaboration between institutions; and maintaining high standards of teaching as well as good quality research (p. 2).
The Report also identifies a number of international trends increased competition from developing countries with a strong commitment to education and training, the growing importance of knowledge in the new economic order, and probable changes to modes of delivery following the development of new information technologies - all of which can be expected to have a significant bearing on higher education over the next two decades. The challenge facing higher education is to respond to these changes while continuing traditional contributions to culture, citizenship and the values of a civilised society (p. 2). A learning society which synthesises these aims has four main purposes:

- to inspire and enable individuals to develop their capabilities to the highest potential levels throughout life, so that they grow intellectually, are well equipped for work, can contribute effectively to society and achieve personal fulfilment;

- to increase knowledge and understanding for their own sake and to foster their application to the benefit of the economy and society;

- to serve the needs of an adaptable, sustainable, knowledge-based economy at local, regional and national levels;

- to play a major role in shaping a democratic, civilised, inclusive society (p. 3)

The Report predicts that demand for higher education in the United Kingdom will continue to grow, and makes a large number of recommendations. These include: increasing participation rates for under-represented groups; placing greater emphasis on enhancing the quality of teaching in higher education; developing clear outcomes statements for different programmes of study; boosting research funding via a range of government initiatives; providing stronger government support for work in the arts and the humanities; encouraging interdisciplinary and collaborative academic activities; providing all students with access to networked desktop and portable computers within the next decade; reviewing pay, conditions of service and policies of staff development; according further education colleges priority in sub-degree provisions and halting the growth of degree level qualifications in these institutions; indexing government support for student living costs against movements in prices and earnings; increasing, over the long term, public spending on higher education in line with the growth in Gross Domestic Product; removing disincentives for part-time learning; making government contributions to tuition costs 
contingent upon income; implementing a system requiring students to make a flat rate contribution of around $25 \%$ of the average cost of higher education tuition (subject to a range of constraints); considering alternative approaches to national accounting to allow the repayable part of loans and grants to students to be treated differently; and establishing a UK-wide independent advisory committee for assessing the state of higher education after five years (and subsequently every ten years).

The authors of the Report admit that some of their recommendations will require substantial developmental work before they can be implemented, and express their concern that organisations not be over-burdened in having to complete too many tasks at once. There is, however, "an immediate short term problem with the funding of higher education". If this is not addressed by the Government, the Report claims, "there is a real danger that some institutions will be severely damaged and that others will take unilateral action, for example through the introduction of supplementary fees, which make it impossible for our long-term vision to be realised" (p. 19). The Report draws attention to the need to reward staff in higher education for their achievements, while also encouraging institutions of higher education to continue responding to national and international challenges. The summary of recommendations concludes on an optimistic note:

We know, from all the contacts we have had in our work, that the value and importance of higher education is widely recognised. We also know that those within higher education are committed to its wellbeing and are willing to embrace change. If all that good will, energy and professionalism can be focused on the developments proposed in this report, we are convinced that UK higher education will match the best in the world over the next 20 years.

\section{A Critical Comparison}

The differences between the Dearing Report and the New Zealand Tertiary Education Review Green Paper are evident not only in the scope of the reviews and their terms of reference, but also in terms of their recognition of the wider social, cultural and historical context(s) for higher education. The Dearing Report was wide in scope and committed to a democratic policy process. The New Zealand tertiary review (of which the Green Paper is a part), by contrast, has been largely an officials-driven process. Consultation has been sporadic and often at the behest of "stakeholders" (this is the Ministry's term). The Green Paper only briefly mentions "The Future Context". The overwhelming concerns are those driven by the logic of efficiency: by the desire to extract greater value from the Government's investment in higher education. Some of the principles on which the Dearing Committee based its deliberations are similar to those underpinning the Green Paper. There is talk, in both cases, about maximising participation, enhancing student choice, maintaining degree standards, improving the effectiveness of teaching and learning, being responsive to employment needs, and promoting fairness in student support. However, the Dearing Committee was concerned not just with "cost-effectiveness" but also questions pertaining to intellectual culture, tradition, the spirit of critical inquiry, the importance of the humanities, the contribution higher education makes to moral and spiritual life, and the upholding of democracy. These dimensions of higher education barely warrant a mention in the Green Paper. While there are many important differences between the two documents, we have selected four for more detailed comment below.

\section{The concept of education}

The Dearing Report and the Green Paper are underpinned by quite different concepts of education. The former, whatever one might say about its vision, at least makes a "philosophical" attempt to place education at the centre of its policy proposals. In the Dearing Report, education is fundamental to the fabric of a new society - and not simply an adjunct to the economy. The society of the future for the Dearing Committee is one committed to learning. The Dearing Report explores, in a rigorous manner, the relationship between learning and social, cultural and economic well-being. The Green Paper, on the other hand, is informed by what we see as an impoverished view of education. There has been a relentless move in recent years to make the New Zealand tertiary education system conform to the rules of the market. The Green Paper does not disrupt this trend. Education, in a marketised system, becomes a commodity to be sold, traded and purchased. "Education", on this view, cannot be distinguished from any other service or product in the marketplace - it has an exchange value like everything else. The notion of education becoming a public good disappears here; education becomes fully privatised and individualised in a marketised, consumer-driven system. 
Of course, once a market model has been embraced all subsequent policy questions - concerning, for instance, the resourcing of tuition, research, governance, and accountability - have ready answers. These answers are based on the principle of individual consumers making continuous choices among competing providers, products and services - with a view to maximising their own interests. A market model cannot address or answer questions that go beyond the logic of individual self-interest. The economic sphere within which this model operates is narrow: questions about the externalities of higher education are avoided. Similarly, traditional questions about the cultural, social and spiritual dimensions of education - and the intrinsic benefits of learning (for both individuals and groups) - disappear. There is, in a fully consumer-driven system, no longer any need to draw distinctions between different modes or forms of education - e.g. "vocational" as distinguished from "academic" - as all activity within the tertiary sphere can ultimately be reduced to a series of transactions between "providers" and "consumers". In all cases, the implied contract is the same: students pay fees for courses, while institutions (or other tertiary organisations) discharge their obligations in providing what the students have paid for. There is no substantive difference between "education" and "training" in such circumstances: these words simply provide different ways of describing (perhaps marketing) the exchange process.

\section{Resourcing}

Governments in many Western countries often claim that they face resourcing demands for the tertiary sector which cannot or ought not to be satisfied entirely from public expenditure. There are a number of ways of responding to this dilemma. Tertiary education can, it might be argued, be fully funded via taxation. The question is whether it is politically viable to do so and, related to this, whether such a system is efficient and just. The notion of covering all tertiary education costs through taxation is not supported in either the Dearing Report or the Green Paper, where two quite different directions are signalled. One route - implied in the Green Paper and made explicit in the earlier leaked document - involves the introduction of parallel forms of privatisation in the state sector. One dimension of this change is the move toward funding individuals through vouchers (or entitlements) rather than bulk-funding institutions. In this way the system becomes more fully consumer oriented: tax dollars are shifted from traditional publicly-funded institutions to students, and, indirectly, to a range of new private education and training establishments. Consistent with this process, the Green Paper talks of the need for providing incentives to allow private educational establishments and organisations to flourish. We might also expect to see further contracting out of educational services and a push to make the resourcing of research more dependent on external agencies. Both of these appear as real possibilities in the leaked document, and neither are ruled out by the Green Paper.

In the Dearing Report, the overall aim is to preserve the nature of public institutions. Universities are seen as having a cultural heritage, a public-service function, and a spiritual dimension. These features of higher education, the Report suggests, should be explicitly recognised, actively maintained, and continuously enhanced. The Report speaks of the need to encourage cooperation, rather than competition, between state institutions, businesses and community groups. Limited privatisation - in the service of upholding a rich educational, cultural and spiritual life within a learning society, rather than as an end in itself - is favoured. Entitlement systems are not excluded from consideration, but if the other recommendations of the Dearing Report were to be enacted, the overall context for the introduction of vouchers would differ markedly from the marketised environment of which such schemes would be a part in New Zealand. In the United Kingdom, voucher schemes would (if the Dearing Committee's findings were taken seriously) be subject to, rather than inherently at odds with, a range of other traditional values and practices in higher education.

\section{Globalisation}

A clear difference between the two documents is evident on the issue of globalisation. The Green Paper contains nothing more than occasional references to living in a rapidly changing world and to positioning New Zealand within the global economy. Yet, the neoliberal policy paradigm represents a commitment to internationalisation of education as a trading commodity and export. Discussion of global issues in the Green Paper is couched within the language of competition. Various forms of regulation (of quality, competition, and ownership monitoring, for example) will still be present, but pressures to seek additional funding from a range of sources will increase for many institutions and organisations. It seems likely that overseas educational institutions and corporations will increasingly vie with local "providers" for student dollars. The danger of eroding cultural traditions 
and resources (including intellectual property) in Aotearoa/New Zealand is very real. Already New Zealand is a signatory to the General Agreement on Trade in Services (GATS). The parameters within which such agreements operate are, as Jane Kelsey (1997) has so effectively demonstrated, very narrow indeed:

There is no place in this new paradigm for the nation-building function of universities; no virtue in an educated population of graduates and academics who are committed to the society which invested in them; no inherent value in education and knowledge which is not highly priced in today's commercial market; no purpose in academic contributions to research, policy, legislation and public debate; no need for expert analysis and public critique which is free from party political and commercial-vested interest; no obligation to comply with the Treaty. These become casualties of the global educational marketplace. (pp. 85-86)

"Taken to its logical conclusion", Kelsey continues, the GATS could produce:

\begin{abstract}
...a global education system run by trans-national education corporations with branches in numerous countries, using uniform computerised teaching modules, based on one dominant value-structure and perspective, serviced by a small mobile staff who move freely between countries, which compete with each other for the education market in each country within which they operate. (pp. 86-87)
\end{abstract}

The Dearing Report recognises that if the United Kingdom is to participate successfully in increasingly competitive international markets, then it must invest both in the education and training of its graduates and in its research base. This acknowledgement is offset, however, by a commitment to maintaining and enhancing the United Kingdom's distinctive cultural heritage and identity within the world order. Higher education is seen as a major contributor to local, regional and economic growth and regeneration. While recognising the fact that higher education is an important "export" in its own right, the Dearing Report also wants to protect the defining elements of its own national system of higher education. The Dearing Committee is, in other words, cautious about opening the system up to full international competition. As the report notes,

Through scholarship and research higher education provides a national resource of knowledge and expertise for the benefit of our international competitiveness and quality of life, and provides a basis for responding to economic and social change through innovation and lifelong learning (p. xx).

\section{The role of the humanities}

In the Green Paper there is no explicit recognition of the role of the humanities and arts, or indeed, of the importance of research per se. The discussion is limited to issues of resourcing and questions about whether all degree "providers" should carry out research. In terms of the current funding system for research, the arts and humanities in New Zealand have suffered when viewed alongside the sciences and technology which, together, are seen as providing the engine for economic growth. Only recently, through the Marsden Fund, have the humanities been entitled to funding. The current funding categories in the science policy regime exclude funding for humanities research. Under the severely restricted view of education implied by a market model, both the intrinsic and the instrumental benefits of the arts and humanities in post-industrial societies tend to be ignored.

By comparison, there is underlying the Dearing Report an explicit recognition of the role of the arts and humanities in contributing both to economic growth and cultural development. The third appendix to the Report (a paper entitled The Need to Invest in Research in Humanities and Arts) recognises, for instance, that the humanities and arts enhance cultural, civic and social experiences while also contributing to the aesthetic quality of life. The paper argues that research in the humanities and arts has been unduly neglected, and that such research contributes to national prosperity and a higher quality of life. Study in the humanities is seen as leading to lifelong benefits for individuals, an enhancement of the mind, and greater access to national and international culture. Humanities graduates, the paper suggests, actively contribute to the construction and preservation of a culturally rich society.

In addition, the paper identifies a number of direct economic benefits - particularly in the rapidly expanding tourism, heritage and leisure industries - associated with work in the humanities. The humanities and arts contribute directly to the maintenance and transmission of different cultural traditions through research in, and management of, libraries, galleries, museums and national monuments. Graduates in the arts and humanities play a significant part in preserving and interpreting heritage in all its forms: "from buildings and 
the landscape to books, manuscripts, paintings, sculpture, music and other media". The paper argues that such graduates will provide the "research and administrative base for a range of increasing opportunities for leisure, in museums, galleries, libraries, theatres, television and film production companies and concert halls". The arts and the humanities are also important in the teaching and learning of English, computation linguistics and translation work. They already have a very significant and direct role to play in the publishing industry and will, in the future, contribute to the major export business represented by education and training (estimated to be worth $£ 7$ billion per year in the UK).

\section{The Hallowed or Hollowed-Out University?}

While there are many other critical contrasts between the Dearing Report and New Zealand's Tertiary Education Review Green Paper, the points of difference identified and discussed above should give some indication of what might be at stake for higher education in the two countries. The Dearing Report acknowledges that in the United Kingdom, as elsewhere in the Western world, universities must adapt to changing circumstances, keep up with advancements in technology, and align (some of) their teaching and research functions with the expressed needs of employers and industry groups. The Report also recognises, however, that a university is more than a commercial enterprise. There is a sensitivity to - indeed an overt emphasis upon the longstanding traditions of scholarship within the humanities, the role of the university in promoting social criticism and debate, and the value of higher education for cultural enrichment. The Green Paper is premised upon a view of education tied to the imperatives of the market. If the vision of higher education implied by the Green Paper becomes a reality, research and teaching in the humanities will only survive if it can be reconfigured along utilitarian lines. With a decline (in real terms) in state spending on universities, the impediments to learning "for its own sake" will be substantial. Higher education will become a terrain for vigorous international competition as "providers" of all kinds seek to secure student dollars.

It has been necessary to speak of an implied vision for higher education in the Green Paper, for, unlike the Dearing Report - with its well-developed notion of "The Learning Society" - the New Zealand document is lacking in detail on many pivotal policy areas. In considering how this skeletal framework for a fully consumer-driven, marketised system of tertiary education might be fleshed out in practice, we believe much might be gained from examining a policy document produced for the Australian higher education review. The document in question is an appendix to the recent West Committee's policy discussion paper, Review of Higher Education Financing and Policy, released in late November 1997. In our view, the appendix brings (if unintentionally) many of the elements of a neo-liberal view of education into clear focus. It conveys what we regard as a deeply distressing vision of higher education - a vision so vivid that critique does not seem necessary. The appendix, in short, serves as its own critique - at least when viewed alongside the alternative vision developed in the Dearing Report - and will be summarised below as an example of what the future might hold for New Zealand if current policy trends continue. The appendix spells out the end of an era of state planning - in essence the end of a public tertiary education system - and argues that the emerging system will be consumer-driven, much more diversified, and part of the global information economy. In an almost total antithesis to the values of the existing system, the system emerging under the dual pressures of the international market and the new communications and information technologies will be one in which highly-specialised, internationally-oriented, privatised university corporations compete to deliver flexible programmes anywhere in the world. Our comments on the appendix will be preceded by a brief overview of the main discussion paper in the West Committee's review of higher education (1997).

The discussion paper itself is unexceptional in many ways. It begins with a preface by Roderick West, the Chair of the Higher Education Review, who asserts two "certainties": first, "the twenty-first century will mark the era of tertiary education and lifelong education for everybody" and, second, there are "extraordinary possibilities in the provision of education through ever-expanding technological advance". These two elements dictate the approach to financing and policy. The paper spells out a vision of "learning for life", a seamless tertiary education environment with commitments to building a culture of learning, civic values, scholarship, preparing graduates, advancing knowledge and skills, "developing the industry", and equity. The paper then lists the principles on which the future should be built:

- Enhancing access - a commitment to universal access;

- Maximising study options by fostering a direct relationship between the student and provider and emphasising student choice; 
- Promoting outcome-based assessment of quality and accountability to students and the taxpayer;

- Maximising the benefits of research in terms of a national strategy;

- Cost-effectiveness of public funding and orientation to the community's needs;

- Fair levels of private contribution.

In the context of identifying forces for change the paper directs its attention to the "digital revolution". The changes wrought by the digital revolution will be so pervasive, the paper maintains, that universities will be forced to rethink fundamentally every aspect of the way in which they provide their services. The increasingly competitive environment that the new technologies will bring will encourage universities to respond to the following questions:

- How can they protect their student numbers against local and international competition?

- Can they afford to develop individual courses and course materials when better quality and less expensive materials could be developed by cooperative action?

- Can they afford to build and maintain expensive support services, such as library services, when better and cheaper services could be provided through collective action?

- Can they afford to continue to invest in large-scale "bricks and mortar" infrastructure ... when new technologies offer cheaper and less expensive means of communicating information to large numbers of people?

- Should they seek to meet all educational needs of students ... or should they focus their energies on areas of greatest expertise, and, therefore, advantage?

The paper goes on to discuss the strengths and weaknesses of the current system before identifying issues and options for the future. The paper expresses the Committee's strong preference for a demand-driven approach to tertiary education policy and financing. This means, of course, a student-centred funding model where students will have access to a "lifetime entitlement" and to income-contingent loans. A student-centred funding model is seen to offer greater flexibility, encourage high quality learning, and promote equity. This would occur in a largely deregulated environment for providers where greater incentives for more private investment are put in place. The Committee also indicates that current university governance structures are not appropriate for a more competitive environment.

The real vision for the discussion paper is provided in the first of the commissioned papers: Australian Higher Education in the Era of Mass Customisation (Appendix 11) by Global Alliance Limited. Global Alliance Limited (GAL) is a Tokyo-based investment bank established in 1995. GAL specialises in providing investment and corporate advisory services, mainly to Japanese and Taiwanese companies, and especially in relation to the information technology sector. GAL has investments on its own account in Internet service providers and related companies.

Its vision is stark and uncompromising. The GAL report proclaims both the end of "the era of homogeneity" under state planning and the beginning of another era which will be consumer-oriented, more diversified and exposed to international competition. The remnants of an era of state planning show that while costs of production are world competitive, productivity incentives are poor and capital management requires reform. The existing providers are protected in the Australian domestic market but not for much longer.

The report identifies the following forces for change: a reduction in public subsidies and increasing fees, the associated shift of power to the consumer, increasing international competitive exposure and changes in the technology of production and consumption. Computers will lower costs of marketing and the provision of customer services while at the same time promoting greater access to learning and enhancing the quality of the learning experience. Back-end systems will be automated and learning systems will increasingly apply computer technologies to allow courses to be delivered over the Web. The effects of these forces will lead to "the hollowing out of the university". The report is worth quoting at some length here:

The vertically integrated university is a product of brand image, government policy, history and historical economies of scale in support services. If government policy is no longer biased in favour of this form, and technology liberates providers from one location, then we would expect to see new forms arising such as multiple outlet vertically integrated specialist schools and web based universities ... Specialist service providers, such as testing companies and courseware developers will arise, as will superstar teachers who are not tied to any one university. Many universities will become marketing and production coordinators or systems integrators. They will no longer all be vertically integrated education versions of the 1929 Ford assembly plant in Detroit (p. 12). 
The overall result of the effects of these combined forces of change will be an increased segmentation of markets, together with further specialisation and customisation in the provision of educational programmes. The new university system will take the form of one of a series of possible business models: a low cost producer university; the Asian middle-class Web university; the "Harvard in Australia" university; or a world specialist school university.

\section{Concluding Remarks}

GAL's report provides the naked neo-liberal underbelly for the West Committee's more muted and "humanist" student-centred funding model. It is a vision that in all its starkness spells out "the new world order" of global competition for national systems of higher education. It certainly seems consistent with the principles and preferred options underlying our own Tertiary Education Review Green Paper. What is unconscionable is that the vision of the future for higher education described by the GAL report and permitted by the Green Paper is seen to be inevitable. Upholding democracy in New Zealand demands that voters - including students and academics - be given a genuine opportunity to raise voices of objection against the direction tertiary education policy appears to be taking in this country.

Criticisms can be made of both the substance of the Green Paper and the process associated with its production. The Dearing report is the product of a very comprehensive and systematic review of higher education policies in the United Kingdom, undertaken by an independent committee of high calibre, over a reasonable period of time. The Dearing Committee's work was well funded. By comparison, the New Zealand Tertiary Education Review Green Paper was prepared within six months by a handful of staff in the Ministry of Education, and was not nearly as ambitious in scope, research orientation or consultation with specialists in the higher education sector. The contrasts between the two reports can be explained in part by the significant differences in the size and resources of the two countries. It might be argued that it would be very difficult in New Zealand to mount a review of similar magnitude to that conducted by the Dearing Committee. Yet the limits of the Green Paper are also deeply ideological in nature. Decisions about tertiary education in New Zealand must be seen in the light of a wider set of policy reforms: in particular, the aggressive programme of privatisation mounted by successive governments over the past decade, underpinned by an economic philosophy of market liberalism and an ethic of competitive individualism. More extensive dialogue with the groups most affected by possible changes in tertiary education was possible, and could have contributed to a much more thorough treatment of many policy issues glossed over in the Green Paper.

The concept of "The Learning Society" certainly captures the commitment to higher and adult education and the need for "perpetual retraining", that lie at the heart of visions of the "post-industrial" or "knowledge" society. The concept also fulfils ideological purposes: it may simply indicate a softer and more human face to a neo-liberal paradigm of globalisation that threatens to turn universities into service and training centres for the world's transnational corporations. At the cultural level, "The Learning Society" seems to encapsulate a desire both to preserve a heritage and to respect the institutional autonomy of universities. Yet in the final analysis, if the notion of "The Learning Society" is predicated upon globalisation as a form of world economic integration, then the autonomy of the cultural sphere will be eroded and statements as to its preservation will amount merely to pious wishes.

The GAL scenario is both technologically determined and market driven. Local or national markets, the GAL authors would have us believe, must give way to international competition. Such assumptions must be contested. Political sovereignty allows us to elect or reject governments on the basis of their economic and social policies. There has never been a time in which more has been at stake for tertiary education in New Zealand. Given what has already been foreshadowed by the leaked Ministry of Education document, if voters wish to retain some of the traditional values on which universities were founded, there will be no time for complacency. Exercising the democratic right to reject further neo-liberal policy reforms will, we suggest, become an increasingly urgent requirement for the survival of a credible higher education system.

Notes

1. See the appendix on externalities in higher education in Dearing (1997). For a critical examination of human capital theory and education, see Fitzsimons and Peters (1994)

2. The ground for policy formulation has subsequently shifted: the Government now intends to publish more than one White Paper. 
3. All page numbers in references to the Dearing Report will be from a printout of the Internet version of the document.

See: <http://www.leeds.ac.uk/educol/ncihe/docsinde.htm>

\section{References}

Association of University Staff of New Zealand. (1997). Submission on the Tertiary Education Review Green Paper.

Bell, D. (1974). The coming of postindustrial society: A venture in social forecasting. Harmondsworth: Penguin.

Boston, J. (1997a). The tertiary education review: Issues and Implications. Paper prepared for a staff seminar at the University of Auckland, October 23.

Boston, J. (1997b). The tertiary education review: A critical appraisal. Paper prepared for the NZUSA Conference, University of Canterbury, August 30.

Dearing, R. (Chair) (1997). Higher education in the learning society. Report of the National Committee of Inquiry into Higher Education (United Kingdom.

< http://www.leeds.ac.uk/educol/ncihe/docsinde.htm>

Fitzsimons, P., \& Peters, M. (1994). Human capital theory and the industry training strategy in New Zealand. Journal of Education Policy, 9(2), 245-266.

Global Alliance Limited. (1997). Australian higher education in the era of mass customisation. Appendix 11 in R. West (Chair) Review of higher education financing and policy. Interim Report of the Higher Education Review Committee (Australia).

Kelsey, J. (1997). The globalisation of tertiary education: Implications of GATS. In M. Peters (Ed.) Cultural politics and the university in Aotearoa/New Zealand. Palmerston North: Dunmore Press.

Machlup, F. (1962). The production and distribution of knowledge in the United States. Princeton: Princeton University Press.

Masuda, Y. (1981). The information society as post-industrial society. Washington, DC: World Future Society.

Ministry of Education. (1997a). A future tertiary education policy for New Zealand: Tertiary education review (green paper). Wellington: Ministry of Education. <http://www.minedu.govt.nz/Tertiary/Review97/ paper/content.htm $>$

Ministry of Education. (1997b). Tertiary education review: Proposals and key decisions. Wellington. (Draft document dated 17 July 1997, leaked to the media.)
Ministry of Education. (1997c). A future qualifications policy for New Zealand (green paper). Wellington: Ministry of Education.

$<$ http://www.minedu.govt.nz/NQF/paper.htm >

Ministry of Education. (1997d). Quality teachers for quality learning: A review of teacher education (green paper). Wellington: Ministry of Education.

Peters, M., \& Roberts, P. (Eds.) (1998 in press). Virtual technologies in tertiary education. Palmerston North: Dunmore Press.

Porat, M. (1977). The information economy: Definition and measurement. Washington, DC: U.S. Department of Commerce.

Touraine, A. (1974). The post-industrial society: Tommorow's social history, classes, conflicts and culture in the programmed society. Trans. L. Mayhew. London: Wildwood House.

Upton, S. (1987). The withering of the state. Wellington: Allen and Unwin.

West, R. (Chair) (1997). Review of higher education financing and policy. Interim Report of the Higher Education Review Committee (Australia).

\section{Thanks}

We are most grateful for a reviewer's particularly detailed and helpful response to the original version of this paper.

\section{The authors}

Michael Peters and Peter Roberts, both of the School of Education at the University of Auckland, share research interests in educational philosophy and critical policy studies. They have published in a wide range of international journals, and have recently co-edited a book, Virtual Technologies in Tertiary Education (to be published in 1998 by Dunmore Press). Michael has also edited a collection entitled Cultural Politics and the University, and served as Academic Vice-President of the Association of University Staff in 1997. Other collaborative projects include their forthcoming book on university futures and the politics of reform, and several articles on the philosophy of cyberspace. 